\title{
THE CASE OF THE WOMEN WITH THE BROKEN HEART
}

\author{
Anna Abelsson \\ Jönköping University, School of Health Sciences, Jönköping, Sweden
}

\begin{abstract}
:
Takotsubo can be detected as a kindred disease, predominantly affecting post-menopausal women. By correctly identifying these patients as having an acute heart failure syndrome, the outcome can be favorable.
\end{abstract}

KEY WORDS: acute myocardial infarction, Takotsubo

Disaster Emerg Med J 2018; 3(2): 67-68

Esther is a 63-year-old woman, working part time in a boutique in the small city where she lives. She has been married to John, also 63-year-old, for 40 years. John works as an electrician for a small company in their city. They have 2 adult daughters with families of their own. Esther and John had a dog. But the dog died 2 weeks ago. Esther was devastated.

On Monday afternoon, Esther got a call at work telling her that John has been badly injured at work. The nurse asked Esther to come to the hospital. When she arrived at the hospital, John had passed away. At 63 years of age, Esther becomes a widow. Esther's heart brakes. Her life is now a traumatic loss, endless sorrow, and indescribable emotional stress.

The rest of the week continues as a blur for Esther. She is feeling depressed, sick to her bones and feels just very tired. She has shortness of breath, a little nausea and on Friday during lunch, her chest pains are becoming intolerable. Her daughter understands that her mother has gotten an acute myocardial infarction and calls for an ambulance.

In the ambulance, Esther is placed on a stretcher. Her vitals are continuously monitored during the short trip to the hospital, pulse, blood pressure, respiratory rate. An ECG shows an ST elevation, signs of a classic acute myocardial infarction. She is given oxygen, Morphine, Nitroglycerin sublingual and Aspirin (Trombyl). She is also given Furosemide as the ambulance nurse sees the shortness of breath as a sign of the beginning of pulmonary edema.

Esther arrives in the hospital, and the ambulance nurses bring her directly to the Percutan Coronary Intervention ( $\mathrm{PCl}$ ) lab for an angiogram.

- Where it is noted that; there is no coronary restriction.

- Where it is noted that; there is no ischemic state of oxygen deficiency in the heart.

The coronary $X$-ray shows instead that the left ventricle assumed a balloon-like shape with a narrow shaft. The heart does not pump regularly, and the left ventricle contractions are uneven and ineffective. What Esther has fallen ill in, is Takotsubo, an unusual form of cardiomyopathy. Takotsubo is known as "Broken heart syndrome". The heart does not actually break, but the lower part of the left ventricle is expanded and has a reduced pump capacity and may, therefore, cause heart failure [1].

Takotsubo is the Japanese term for Octopus pot referring to the heart-shaped fisherman's octopus trap (Fig. 1). The cause of the disease is not known, but it has been speculated that it might have various reasons. Acute stress alone, or in combina- 


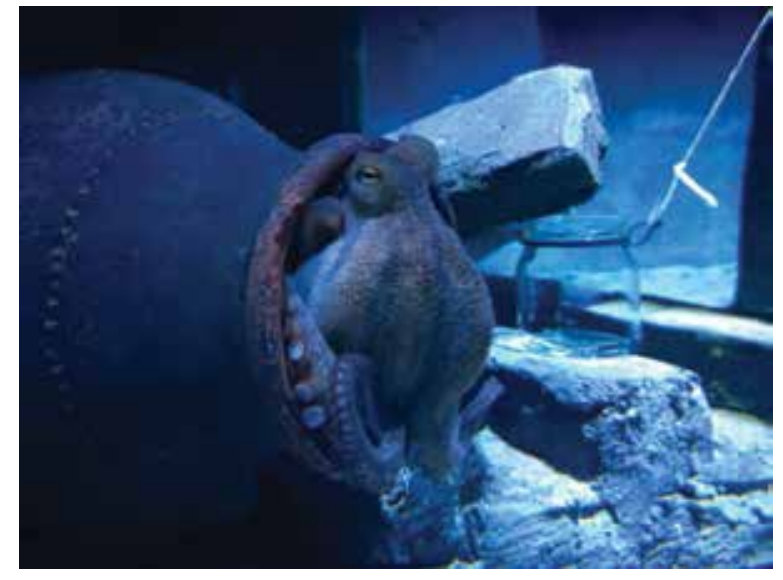

FIGURE 1. Octopus pot attached to a long rope and dropped to the bottom of the sea for the octopuses to accommodate themselves in. Trapped when lifted to the surface by fishermen.

tion with prolonged stress, has been identified as a main cause in Takotsubo. Takotsubo is triggered by acute, emotional stress which has been caused by the personal traumatic event, surprise parties, public speaking, medical procedures and armed robbery [2-4]. Other examples described in research are the Japanese earthquakes in 2004 [5], the terrorist attack in Tokyo subway 1995 [6] and the New Zealand earthquakes 2011 [7].

Stress mediated from the brain through catecholamines in the blood damaging the heart muscle cells is one explanation. This hypothesis is based on that the recipient cells on which stress hormones settle are concentrated just at the tip of the left ventricle. Another cause is the stress mediated from the brain by direct impact to the nerve-threads in the heart. Activation of the sympathetic nervous system causes reduced contractile function in the myocardium (ischemia caused by catecholamine-induced spasm in coronary arteries) $[2,4]$. One can say that Takotsubo starts in the brain but strikes in the heart

Almost $90 \%$ of the patients with broken hearts are women, most of them after menopause. The explanation could be that postmenopausal women have lost their protective effect of estrogens which include the protection of circulating catecholamines. Nevertheless, Takotsubo is often linked to physical or mental stress before the onset of illness [4]. Cases involving children has also been reported $[8,9]$.

The prognoses are good with $95 \%$ of the patients recovering completely. Usually, the heart muscle regains its normal shape within three to eight weeks. The patient will need psychological and/or cognitive support to reduce the risk of relapse [2, 3].

\section{CONCLUSIONS}

We can foresee and be prepared for the case of the women with the broken heart, which can be mistaken for an acute myocardial infarction, when we meet the newly become widow, the mother who just lost her adult child or generally, a person affected by an overwhelming, stressful event that struck life in ruins.

Conflict of interest: None declared.

\section{REFERENCES}

1. Dote K, Sato H, Tateishi H, et al. Myocardial stunning due to simultaneous multi vessel coronary spasms: a review of 5 cases. J Cardiol. 1991; 21(2): 203-214.

2. Prasad A, Lerman A, Rihal CS. Apical ballooning syndrome (Tako-Tsubo or stress cardiomyopathy): a mimic of acute myocardial infarction. Am Heart J. 2008; 155(3): 408-417, doi: 10.1016/j.ahj.2007.11.008, indexed in Pubmed: 18294473.

3. Weiner MM, Asher DI, Augoustides JG, et al. Takotsubo Cardiomyopathy: A Clinical Update for the Cardiovascular Anesthesiologist. J Cardiothorac Vasc Anesth. 2017; 31(1): 334-344, doi: 10.1053/j. jvca.2016.06.004, indexed in Pubmed: 27546831.

4. Y-Hassan S, Tornvall P. Epidemiology, pathogenesis, and management of takotsubo syndrome. Clin Auton Res. 2018; 28(1): 53-65, doi: 10.1007/s10286-017-0465-z, indexed in Pubmed: 28917022.

5. Watanabe $H$, Kodama $M$, Okura $Y$, et al. Impact of earthquakes on Takotsubo cardiomyopathy. JAMA. 2005; 294(3): 305-307, doi: 10.1001/jama.294.3.305, indexed in Pubmed: 16030274.

6. Kato T, Yoshimoto $N$, Sawano $M$, et al. Coronary vasospasm in a patient suffering from sarin poisoning. Am J Emerg Med. 2000; 18(1): 113-114, indexed in Pubmed: 10674548.

7. Chan C, Bridgman P, Troughton R. Favorable 5-Year Outcome of 21 Takotsubo Stress Cardiomyopathy Cases Triggered by an Earthquake. J Am Coll Cardiol. 2016; 68(8): 877, doi: 10.1016/j.jacc.2016.05.074, indexed in Pubmed: 27539184.

8. Mrozek S, Srairi M, Marhar F, et al. Successful treatment of inverted Takotsubo cardiomyopathy after severe traumatic brain injury with milrinone after dobutamine failure. Heart Lung. 2016; 45(5): 406-408, doi: 10.1016/j.hrtlng.2016.06.007, indexed in Pubmed: 27402629.

9. Toce MS, Farias M, Bruccoleri R, et al. A case report of reversible Takotsubo cardiomyopathy after amphetamine/dextroamphetamine ingestion in a 15-year-old adolescent girl. J Pediatr. 2017; 182: 385-388. e3, doi: 10.1016/j.jpeds.2016.11.038, indexed in Pubmed: 27979580. 